\title{
Recharging behavior of nitrogen-centers in $\mathrm{ZnO}$
}

Jan M. Philipps, Jan Eric Stehr, Irina Buyanova, Marianne C. Tarun, Matthew D. McCluskey, Bruno K. Meyer and Detlev M. Hofmann

\section{Linköping University Post Print}

\section{Tweet}

N.B.: When citing this work, cite the original article.

Original Publication:

Jan M. Philipps, Jan Eric Stehr, Irina Buyanova, Marianne C. Tarun, Matthew D. McCluskey, Bruno K. Meyer and Detlev M. Hofmann, Recharging behavior of nitrogen-centers in ZnO, 2014, Journal of Applied Physics, (116), 063701.

http://dx.doi.org/10.1063/1.4892632

Copyright: American Institute of Physics (AIP) http://www.aip.org/

Postprint available at: Linköping University Electronic Press http://urn.kb.se/resolve?urn=urn:nbn:se:liu:diva-109926 


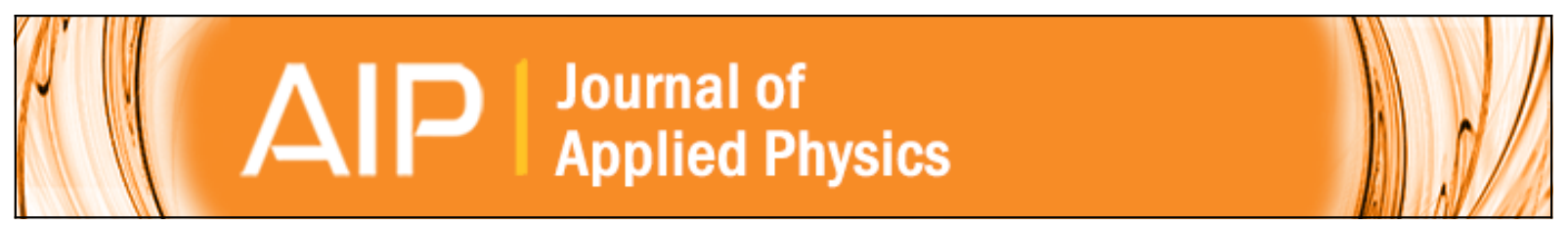

\section{Recharging behavior of nitrogen-centers in $\mathrm{ZnO}$}

Jan M. Philipps, Jan E. Stehr, Irina Buyanova, Marianne C. Tarun, Matthew D. McCluskey, Bruno K. Meyer, and Detlev M. Hofmann

Citation: Journal of Applied Physics 116, 063701 (2014); doi: 10.1063/1.4892632

View online: http://dx.doi.org/10.1063/1.4892632

View Table of Contents: http://scitation.aip.org/content/aip/journal/jap/116/6?ver=pdfcov

Published by the AIP Publishing

\section{Articles you may be interested in}

Neutral nitrogen acceptors in $\mathrm{ZnO}$ : The 67Zn hyperfine interactions

J. Appl. Phys. 115, 103703 (2014); 10.1063/1.4867736

Electron paramagnetic resonance and photo-electron paramagnetic resonance investigation on the recharging of the substitutional nitrogen acceptor in $\mathrm{ZnO}$

J. Appl. Phys. 112, 103511 (2012); 10.1063/1.4765729

Lithium related deep and shallow acceptors in Li-doped $\mathrm{ZnO}$ nanocrystals

J. Appl. Phys. 107, 024311 (2010); 10.1063/1.3275889

Physical characterization of $\mathrm{ZnO}$ nanorods grown on $\mathrm{Si}$ from aqueous solution and annealed at various atmospheres

J. Vac. Sci. Technol. B 23, 2347 (2005); 10.1116/1.2102967

Investigation of radiative and nonradiative trap centers in ZnSe:Al layers grown by molecular beam epitaxy J. Vac. Sci. Technol. B 22, 1475 (2004); 10.1116/1.1755713

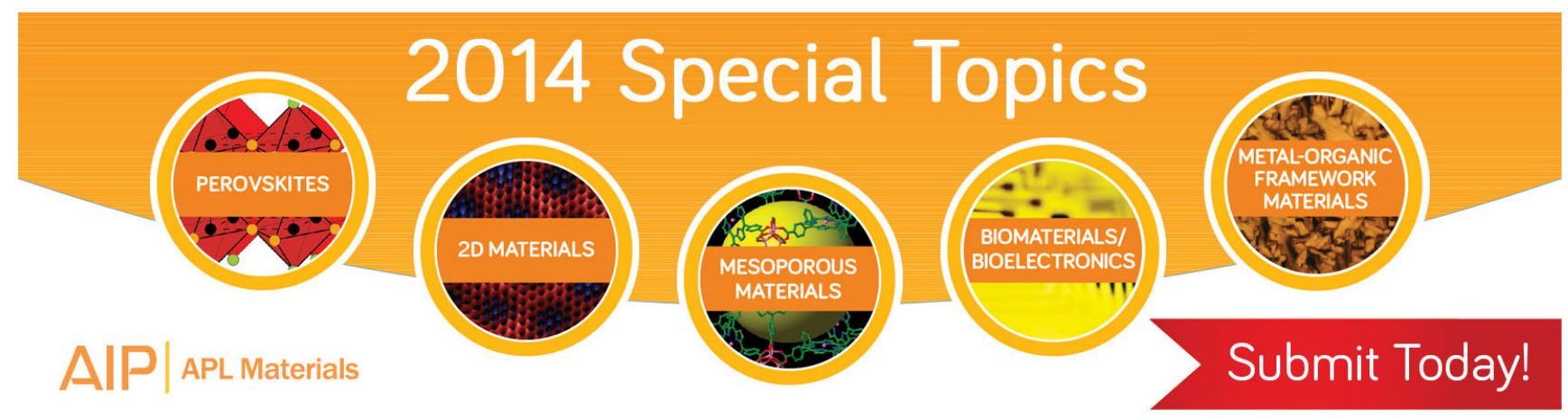




\title{
Recharging behavior of nitrogen-centers in $\mathrm{ZnO}$
}

\author{
Jan M. Philipps, ${ }^{1, a)}$ Jan E. Stehr, ${ }^{2}$ Irina Buyanova, ${ }^{2}$ Marianne C. Tarun, ${ }^{3}$ \\ Matthew D. McCluskey, ${ }^{3}$ Bruno K. Meyer, ${ }^{1}$ and Detlev M. Hofmann ${ }^{1}$ \\ ${ }^{1}$ I. Physikalisches Institut, Justus-Liebig-Universitaet Giessen, D-35392 Giessen, Germany \\ ${ }^{2}$ Department of Physics, Chemistry and Biology, Linkoeping University, 58183 Linkoeping, Sweden \\ ${ }^{3}$ Department of Physics and Astronomy and Materials Science Program, Washington State University, \\ Pullman, Washington 99164-2814, USA
}

(Received 5 June 2014; accepted 29 July 2014; published online 8 August 2014)

Electron Paramagnetic Resonance was used to study $\mathrm{N}_{2}$-centers in $\mathrm{ZnO}$, which show a 5-line spectrum described by the hyperfine interaction of two nitrogen nuclei (nuclear spin $I=1,99.6 \%$ abundance). The recharging of this center exhibits two steps, a weak onset at about $1.4 \mathrm{eV}$ and a strongly increasing signal for photon energies above $1.9 \mathrm{eV}$. The latter energy coincides with the recharging energy of $\mathrm{N}_{\mathrm{O}}$ centers (substitutional nitrogen atoms on oxygen sites). The results indicate that the $\mathrm{N}_{2}$-centers are deep level defects and therefore not suitable to cause significant hole-conductivity at room temperature. (C) 2014 AIP Publishing LLC.

[http://dx.doi.org/10.1063/1.4892632]

\section{INTRODUCTION}

Nitrogen doping has been suggested to be a way to obtain p-type conductive $\mathrm{ZnO}$. In a simple model, one assumes that nitrogen substitutes an oxygen atom in the crystal lattice and thus causes an acceptor. First evidence for nitrogen incorporation in $\mathrm{ZnO}$ was found by Carlos et al. in 2001 using Electron Paramagnetic Resonance technique (EPR). ${ }^{1}$ The hope was that the recharging level of the nitrogen acceptors is shallow enough to accept electrons from the valence band and to promote hole conductivity. This hope was nourished from the circumstance that the samples treated with nitrogen showed in many cases a shallow donor to shallow acceptor pair (DAP) type of photoluminescence. Shallow (residual) donors are omnipresent in $\mathrm{ZnO}$ and therefore it seemed plausible that nitrogen is related to the shallow acceptor. An acceptor level position of $\mathrm{E}_{\mathrm{vb}}+170 \mathrm{meV}$ was estimated from the experiments. ${ }^{2}$ Arguments opposing this assignment came from problems to reproduce the results, which hindered a clear quantification, as well as from optical measurements. ${ }^{3}$ EPR and photo-EPR investigations eventually revealed that substitutional nitrogen centers $\left(\mathrm{N}_{\mathrm{O}}\right)$ are deep defects with a recharging level $1.3 \mathrm{eV}$ above the valence band. ${ }^{4}$

In the following, it was considered that nitrogen-pair centers or complexes consisting of nitrogen and vacancies or hydrogen atoms might act as the shallow acceptors causing the shallow DAP-PL. However, performing model calculations for such species the results for their recharging properties (being donor or acceptor) and the energy position of the recharging levels were strongly depending on the theoretical method used. ${ }^{5}$ Nickel et al. calculated that $\mathrm{N}_{2}$ causes localized states in the band gap either by forming an $\mathrm{N}_{2} \mathrm{O}$ molecule or by breaking a $\mathrm{Zn}-\mathrm{O}$ bond. ${ }^{6}$ The latter was calculated to have a level about $170 \mathrm{meV}$ above the valence band. Liu et al. ${ }^{7}$ calculated that $\mathrm{N}_{\mathrm{O}}-\mathrm{V}_{\mathrm{Zn}}$ shallow acceptors complexes

a)jan.m.philipps@physik.uni-giessen.de can evolve from the double donor state of $\mathrm{N}_{\mathrm{Zn}}-\mathrm{V}_{\mathrm{O}}$. Recently, Lambrecht and Boonchun ${ }^{5}$ brought $\mathrm{N}_{2}^{+}$located on the $\mathrm{Zn}$ site into play. Other $\mathrm{Zn}$ site configurations such as $\left(\mathrm{N}_{\mathrm{O}}\right)_{\mathrm{Zn}},\left(\mathrm{N}_{2}\right)_{\mathrm{Zn}},\left(\mathrm{NH}_{4}\right)_{\mathrm{Zn}}$ were also considered and calculated to be acceptors in $\mathrm{ZnO}{ }^{8}$

Compared to these promising calculations for nitrogen related shallow acceptors the experimental evidence for the existence of such centers is quite limited. By EPR, it was also possible to identify $\mathrm{N}_{2}$-pair centers which were considered to be acceptors with probably deep level character. ${ }^{9}$

This situation motivated us to investigate the recharging behavior of the $\mathrm{N}_{2}$ centers in more detail by photo-EPR. We find $\mathrm{N}_{\mathrm{O}}$ and $\mathrm{N}_{2}$ centers being present in our samples and upon photon irradiation with energies larger than $1.9 \mathrm{eV}$ both signals were greatly enhanced. However, for the $\mathrm{N}_{2}$ centers a first photo response was noticed at energies greater than $1.4 \mathrm{eV}$.

\section{EXPERIMENTAL}

$\mathrm{ZnO}$ bulk crystals were grown via a seeded chemical vapor transport method in an ammonia ambient, which provided nitrogen as well as hydrogen dopants. ${ }^{10}$ The crystals are c-oriented and have a cloudy brownish appearance, which can be taken as evidence for an inhomogeneous impurity distribution.

EPR experiments were carried out on a commercial Bruker EPR $300 \mathrm{E}$ spectrometer with a modulation amplitude of $0.5 \mathrm{G}$ and a microwave frequency of $9.5 \mathrm{GHz}$. All measurements were performed in liquid Helium at $4.2 \mathrm{~K}$ and results will be shown with the external magnetic field perpendicular to the crystallographic $\mathrm{c}$-axis $(\mathrm{B} \perp \mathrm{c})$.

\section{RESULTS AND DISCUSSION}

In the absence of photon irradiation, two EPR signals could be observed in the spectrum (see Fig. 1(a)). The single signal on the high-field side at $g \approx 1.958$ is the well known shallow donor in $\mathrm{ZnO}{ }^{11}$ 


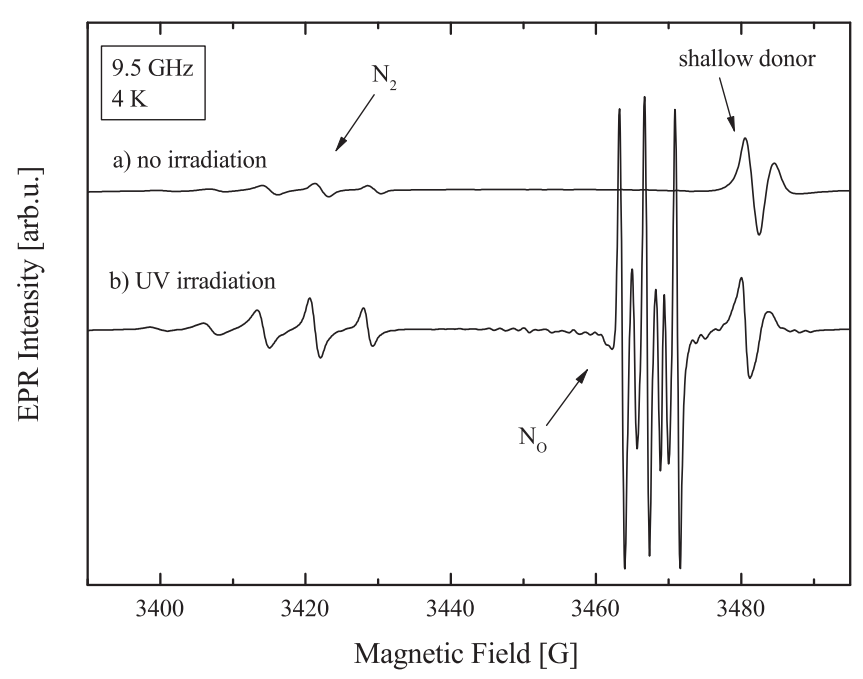

FIG. 1. EPR spectrum of $\mathrm{ZnO}: \mathrm{N}$ (a) taken without irradiation and (b) during UV illumination. The five-line signal and the single line on the high-field side in both spectra are attributed to $\mathrm{N}_{2}$ molecules and shallow donors, respectively. The three-line signal seen in the lower spectrum stems from substitutional $\mathrm{N}_{\mathrm{O}}$ defects.

The second group of signals centered at $g \approx 1.996$ is split into five lines with intensity ratio $1: 2: 3: 2: 1$. This structure is caused by a hyperfine coupling of an EPR active electron to two nitrogen atoms $(I=1$, natural abundance 99.6\%). In agreement to the results of Garces et al. we determine the spin Hamiltonian parameters of the $\mathrm{N}_{2}$ center to $g_{\|}=2.0036$, and $g_{\perp}=1.9935$ for the Zeeman splitting and $A_{\|}=9.8 \mathrm{MHz}$, and $A_{\perp}=20.1 \mathrm{MHz}$ for the hyperfine parameters, assuming a spin of $S=1 / 2$ for the system. ${ }^{9}$ Comparing these parameters to those of the $\mathrm{N}_{\mathrm{O}}$ centers $\left(g_{\|}=1.995\right.$, $g_{\perp}=1.963$ and $A_{\|}=81.1 \mathrm{MHz}, A_{\perp}=8.5 \mathrm{MHz}$ ) one finds that the anisotropy for the $\mathrm{N}_{2} g$-values is smaller and the hyperfine interaction constants indicate a higher localization of the spin density in the basal plane. Thus, it was suggested that one nitrogen of the $\mathrm{N}_{2}$ molecule is substituting for one oxygen ion and the other is an adjacent interstitial oriented along the c-axis. In the paramagnetic form of the molecule, the unpaired spin occupies a $\sigma$-like bonding orbital and has nearly equal interactions with the two nitrogen nuclei. ${ }^{9}$

Upon irradiation with UV light (Fig. 1(b)), a new group of signals appears centered at $g \approx 1.966$. It consists of three strong lines with almost equal intensities and is caused by hyperfine coupling of an electron to a single nitrogen atom. This nitrogen atom is substituting an oxygen anion and hence is forming the $\mathrm{N}_{\mathrm{O}}$ center. Most recently, Golden et al. studied the numerous small lines, which can be seen on the left and right side of the $\mathrm{N}_{\mathrm{O}}$ signal in Fig. 1(b). ${ }^{12}$ They attributed these signals to hyperfine interaction of the $\mathrm{N}_{O}$ center with axial and nonaxial $\mathrm{Zn}$ atoms (nuclear spin $I=5 / 2$, natural abundance $4.1 \%$ ). The lines in between the major $\mathrm{N}_{\mathrm{O}}$ signals result from forbidden transitions, which were discussed in prior studies. $^{4}$

After illumination both the $\mathrm{N}_{2}$ and the $\mathrm{N}_{\mathrm{O}}$ signals are found to be very stable at $4 \mathrm{~K}$ and persist for a long time (up to hours). Heating the sample up to room temperature restores the initial state in which only the $\mathrm{N}_{2}$ resonances are observable.
Most interestingly, illumination increases the intensity of the $\mathrm{N}_{2}$ signal by a factor of about ten compared to its intensity in darkness. This behavior is somewhat surprising as Garces et al. have reported a nearly complete quenching of the $\mathrm{N}_{2}$ signal upon irradiation. ${ }^{9}$

Estimating the concentrations of the $\mathrm{N}_{2}$ and the $\mathrm{N}_{\mathrm{O}}$ centers from the EPR signal-area we find that the concentration of paramagnetic $\mathrm{N}_{\mathrm{O}}$ centers is roughly four times higher than that of the $\mathrm{N}_{2}$ centers, with the latter being in the upper $10^{17} \mathrm{~cm}^{-3}$ range.

To further investigate the recharging phenomenon, we performed systematic photo-EPR measurements. For this purpose, the sample was illuminated with light of varying photon energy using a halogen bulb lamp and multiple absorption filters. Initial conditions were restored after each recharging experiment. In Fig. 2, the EPR intensity of the molecular nitrogen defect (full symbols) as well as the intensity of the single nitrogen defect (open symbols) are plotted versus the energy of the incident photons. For the $\mathrm{N}_{\mathrm{O}}$ center signals, we find a strong increase in intensity for photon energies above $1.9 \mathrm{eV}$. For the $\mathrm{N}_{2}$ centers, the signals start rising already above $1.4 \mathrm{eV}$, but they also exhibit a strong increase at $1.9 \mathrm{eV}$ as the $\mathrm{N}_{\mathrm{O}}$ centers do.

The drawn line gives the calculation of the optical crosssection as described by Stehr et al. ${ }^{4} \mathrm{We}$ obtain a very similar result for the recharging of the $\mathrm{N}_{\mathrm{O}}$ defect in the samples used here compared to their earlier work, where the optical ionization energy $\mathrm{E}_{\text {opt }}$ was calculated to be $2.1 \mathrm{eV}$.

The weak increase of the $\mathrm{N}_{2}$ signal for photon irradiation at $1.4 \mathrm{eV}$ is likely to be caused by an electron capture from the valence band. The fact that there is no significant enhancement observable at lower photon energies proves that molecular nitrogen indeed forms a deep center in the $\mathrm{ZnO}$ band gap.

From Fig. 2, it is easy to see that the strong optical absorption starting at about $1.9 \mathrm{eV}$ is almost identical for both defect species. This leads to the assumption that both

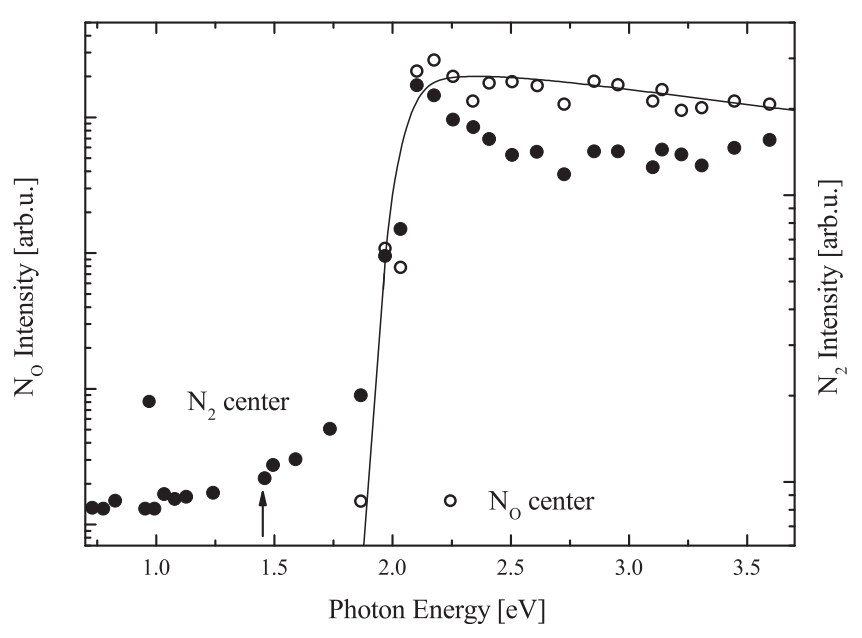

FIG. 2. Photo-EPR intensities of the $\mathrm{N}_{\mathrm{O}}$ defect (open symbols) and the $\mathrm{N}_{2}$ defect (closed symbols). Both nitrogen centers show a steep increase in intensity for photon energies of about $1.9 \mathrm{eV}$. The $\mathrm{N}_{2}$ center also exhibits a weak onset at $1.4 \mathrm{eV}$. The calculation of the optical cross-section for the $\mathrm{N}_{O}$ center (solid line) is in good agreement with the recharging behavior found by Stehr et al. ${ }^{4}$ 


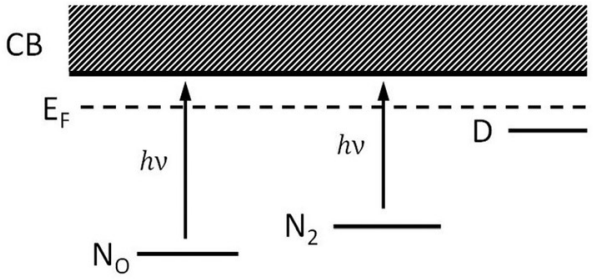

a)

VB

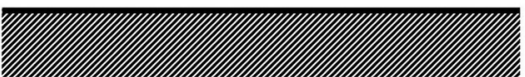

CB

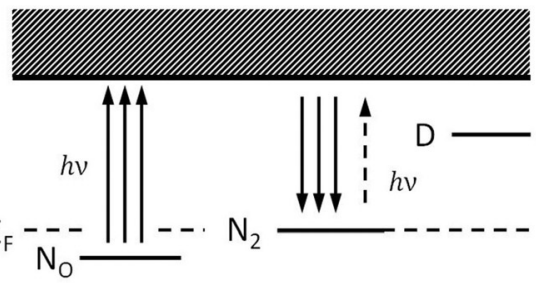

b)

VB

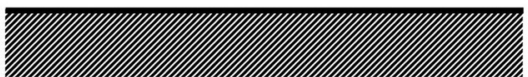

FIG. 3. Schematic overview for the energetic levels for the nitrogen centers in the band gap. In (a) the situation is shown for areas with Fermi level close to the conduction band, while (b) shows the energy positions in areas with high concentration of nitrogen centers and thus lower Fermi level. recharging effects are linked to each other. As the recharging behavior of the $\mathrm{N}_{\mathrm{O}}$ centers observed here is very similar to the behavior reported by Stehr et al., it is very likely that the recharging of the $\mathrm{N}_{2}$ centers above $1.9 \mathrm{eV}$ is dominated by the $\mathrm{N}_{\mathrm{O}}^{-} \rightarrow \mathrm{N}_{\mathrm{O}}+e_{\mathrm{cb}}$ process.

A plausible explanation for the recharging of the $\mathrm{N}_{2}$ centers is given by the following mechanism:

1) Starting at an energy of about $1.9 \mathrm{eV}$ electrons in $\mathrm{N}_{\mathrm{O}}$ states get excited to the conduction band, hence converting the defect into its paramagnetic state $\left(\mathrm{N}_{\mathrm{O}}\right.$ signal rises).

2) Excited electrons in the conduction band relax into free states in the $\mathrm{N}_{2}$ defects, converting them into a paramagnetic state $\left(\mathrm{N}_{2}\right.$ signal rises).

3) Charge carriers are trapped in $\mathrm{N}_{\mathrm{O}}$ and $\mathrm{N}_{2}$ defects and cannot leave this states (EPR signals persist for very long time).

4) Heating up the sample releases the trapped carriers from the defects restoring the initial conditions $\left(\mathrm{N}_{\mathrm{O}}\right.$ signal vanishes, $\mathrm{N}_{2}$ signal decreases).

The crucial step in this mechanism is (2). This requirement can be met, if the recombination rate for conduction band electrons to the $\mathrm{N}_{2}$ defects is much higher than for the competing excitation process. As we found the concentration of $\mathrm{N}_{\mathrm{O}}$ centers to be much higher than for the $\mathrm{N}_{2}$ centers the absorption by $\mathrm{N}_{\mathrm{O}}$ centers could provide conduction band electrons at a sufficiently high rate to outweigh the optical excitation process of the $\mathrm{N}_{2}$ defects.

We observed that the five-line signal from the $\mathrm{N}_{2}$ center is already present in darkness and yet rises with illumination. This means that there have to be $\mathrm{N}_{2}$ molecules in both charge states present at equilibrium, i.e., the Fermi level is located at or near the $\mathrm{N}_{2}$ level in the band gap. However, if the Fermi level was pinned to the $\mathrm{N}_{2}$ defect level in the whole sample, there should be no shallow donor signal observable in EPR measurements without illumination. Thus, we have to consider areas with different Fermi level positions in the samples. On the one hand, there are areas with low Fermi energy, most likely pinned to the $\mathrm{N}_{2}$ centers. On the other hand, there are also areas in which the $\mathrm{ZnO}$ samples maintain their typical n-type behavior with a Fermi level close to the conduction band. As we did not observe any hints of transition metal ions in EPR measurements, we assume a high concentration of $\mathrm{N}_{\mathrm{O}}$ centers in areas of lower Fermi level, which act as acceptors in $\mathrm{ZnO}$. This coincides with the inhomogeneous optical appearance of the $\mathrm{ZnO}$ crystals.
Figure 3(a) shows a sketch of the energetic levels in the band gap as well as the considered optical transitions for a domain of Fermi energy close to the conduction band. Here the concentration of shallow donors dominates and the material remains in its $\mathrm{n}$-type character. Irradiation $(h \nu$, solid arrows) excites electrons from the $\mathrm{N}_{\mathrm{O}}$ defect level as well as from the deep $\mathrm{N}_{2}$ level into the conduction band.

In Fig. 3(b), the energetic levels are sketched for domains with high concentration of nitrogen defects and hence low Fermi energy. As the concentration of $\mathrm{N}_{\mathrm{O}}$ was

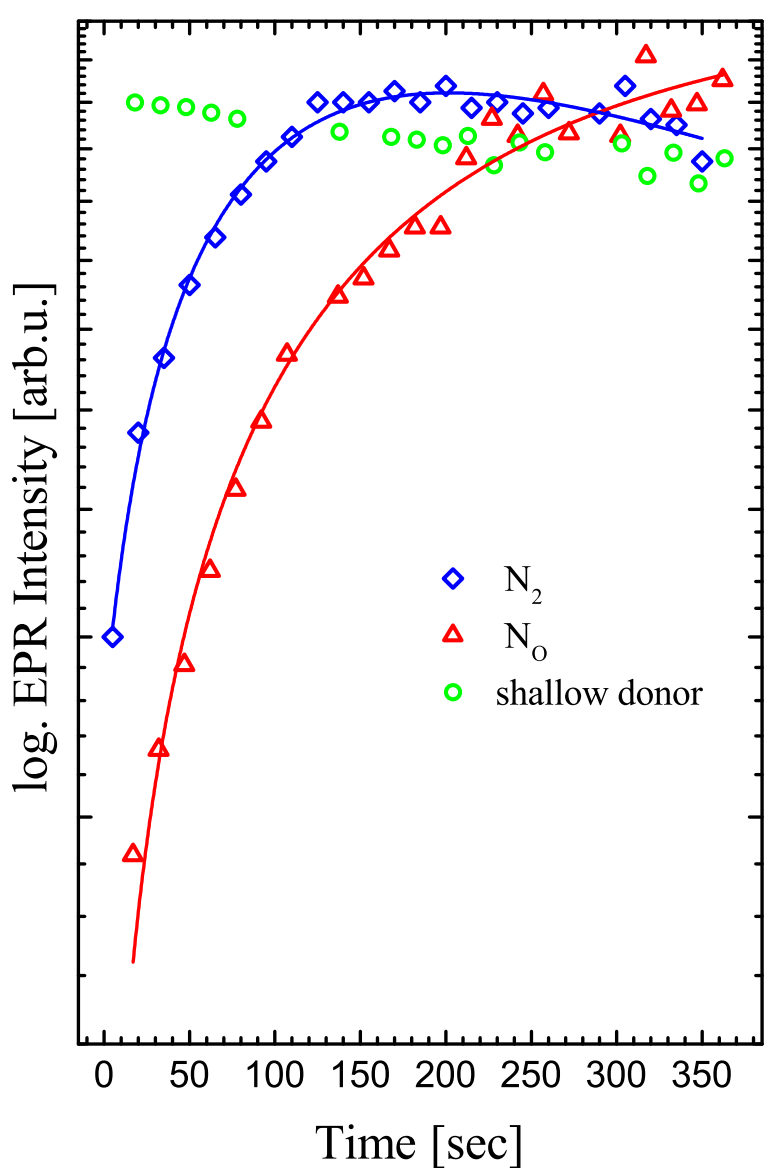

FIG. 4. Transient photo-EPR intensities of the $\mathrm{N}_{\mathrm{O}}$ defect (open triangles), the $\mathrm{N}_{2}$ defect (open diamonds) and the shallow donor (open circles). The solid lines are the best fits for the nitrogen centers. For the substitutional nitrogen $\mathrm{N}_{\mathrm{O}}$ the best fit is a mono-exponential slope, which indicates a direct recharging process. The molecular nitrogen center $\mathrm{N}_{2}$ is fitted best using a bi-exponential slope indicating a non-direct recharging mechanism. 
found to be much higher than the concentration of $\mathrm{N}_{2}$ the optical excitation and the following-up recombination process outweigh the optical absorption of the $\mathrm{N}_{2}$ defects (dashed arrow in Fig. 3(b)). In this model, the $\mathrm{N}_{2}$ center is acting like a deep donor in $\mathrm{ZnO}$. The paramagnetic state in this case would be the $\mathrm{N}_{2}^{0}$ state, while $\mathrm{N}_{2}^{+}$would be the nonparamagnetic charge state. However, an unambiguous assignment of charge states is not possible from the current stage of experimental data.

In order to prove our proposed model, we performed transient photo-EPR experiments. These experiments open up the possibility to determine whether the recharging behavior of the observed photo transition is direct or indirect. To perform the transient photo-EPR experiments, the magnetic field position is kept at a constant value and the EPR signal intensity is monitored as a function of the time. While a mono-exponential slope of this signal indicates a direct recharging behavior, a non mono-exponential slope indicates a non-direct recharging behavior. Figure 4 depicts the transient photo-EPR signals for both substitutional nitrogen $\left(\mathrm{N}_{\mathrm{O}}\right)$ and nitrogen molecules $\left(\mathrm{N}_{2}\right)$ as well as for the shallow donor. The $\mathrm{N}_{\mathrm{O}}$ signal can be fitted best with a mono-exponential behavior indicating a direct recharging process, which is in agreement with the results of Stehr et al. ${ }^{4}$ The $\mathrm{N}_{2}$ signal, however, cannot be fitted by a mono-exponential model; instead it exhibits a bi-exponential behavior indicating a non-direct recharging process. These results are consistent with our proposed model and prove that $\mathrm{N}_{\mathrm{O}}$ is involved in the $\mathrm{N}_{2}$ recharging process.

Moreover, in the frame of this interpretation, it is not only possible to explain our experimental results but also to bring them in line with the results found in the work by Garces et al. Assuming that their samples exhibit a more balanced distribution of nitrogen defects it seems natural that the recharging process of the molecular $\mathrm{N}_{2}$ defect is not governed by the $\mathrm{N}_{\mathrm{O}}$ center. In this case only Fig. 3(a) applies and the $\mathrm{N}_{2}$ signals quench by optical excitation of charge carriers to the conduction band.

\section{CONCLUSION}

In this article, we have shown the results of EPR and photo-EPR experiments on nitrogen doped $\mathrm{ZnO}$ volume crystals. The results found confirm that substitutional nitrogen $\left(\mathrm{N}_{\mathrm{O}}\right)$ forms a deep acceptor level in $\mathrm{ZnO}$. For the molecular nitrogen center $\left(\mathrm{N}_{2}\right)$, we found a weak onset in photoEPR measurements for photon energies of $1.4 \mathrm{eV}$ as well as a strong increase in intensity at about $1.9 \mathrm{eV}$. These results show that $\mathrm{N}_{2}$ centers form deep levels in the band gap of $\mathrm{ZnO}$ as well and therefore cannot be responsible in the previously observed DAP-PL recombination.

A model involving inhomogeneous distribution of nitrogen centers in the samples was proposed to explain the results found here as well as by other groups.

${ }^{1}$ W. Carlos, E. Glaser, and D. Look, Physica B: Condens. Matter 308-310, 976 (2001).

${ }^{2}$ A. Zeuner, H. Alves, D. Hofmann, B. Meyer, A. Hoffmann, U. Haboeck, M. Strassburg, and M. Dworzak, Phys. Status Solidi B 234, R7 (2002).

${ }^{3}$ M. C. Tarun, M. Z. Iqbal, and M. D. McCluskey, AIP Adv. 1, 022105 (2011).

${ }^{4}$ J. E. Stehr, D. M. Hofmann, and B. K. Meyer, J. Appl. Phys. 112, 103511 (2012).

${ }^{5}$ W. R. L. Lambrecht and A. Boonchun, Phys. Rev. B 87, 195207 (2013).

${ }^{6}$ N. H. Nickel and M. A. Gluba, Phys. Rev. Lett. 103, 145501 (2009).

${ }^{7}$ L. Liu, J. Xu, D. Wang, M. Jiang, S. Wang, B. Li, Z. Zhang, D. Zhao, C.-X. Shan, B. Yao, and D. Z. Shen, Phys. Rev. Lett. 108, 215501 (2012).

${ }^{8}$ J. Bang, Y. Y. Sun, D. West, B. K. Meyer, and S. B. Zhang, "Zinc-site nitrogen acceptors in ZnO," J. Mater. Chem. C (submitted).

${ }^{9}$ N. Y. Garces, L. Wang, N. C. Giles, L. E. Halliburton, G. Cantwell, and D. B. Eason, J. Appl. Phys. 94, 519 (2003).

${ }^{10}$ S. J. Jokela, M. C. Tarun, and M. D. McCluskey, Physica B: Condens. Matter 404, 4810 (2009).

${ }^{11}$ J. E. Stehr, B. K. Meyer, and D. M. Hofmann, Appl. Magn. Reson. 39, 137 (2010).

${ }^{12}$ E. M. Golden, S. M. Evans, L. E. Halliburton, and N. C. Giles, J. Appl. Phys. 115, 103703 (2014). 